\title{
Numerical Simulation and Field Measurement Analysis of Fracture Evolution and Seepage Response of Key Aquiclude Strata in Backfill Mining
}

\author{
Qiang Sun $\mathbb{D}^{1,2}$ Yong Chen, ${ }^{3}$ Jianli Huang, ${ }^{3}$ Dan Ma, ${ }^{1}$ Cunli Zhu $\mathbb{D}^{1}$ and Yue Liu ${ }^{1}$ \\ ${ }^{1}$ School of Mines, China University of Mining \& Technology, Xuzhou, 221116 Jiangsu, China \\ ${ }^{2}$ State Key Laboratory for Geomechanics and Deep Underground Engineering, China University of Mining \& Technology, Xuzhou, \\ 221116 Jiangsu, China \\ ${ }^{3}$ Yanzhou Coal Mining Company Limited, Jining, 272101 Shandong, China
}

Correspondence should be addressed to Qiang Sun; kkysun@126.com

Received 3 August 2021; Accepted 29 November 2021; Published 13 December 2021

Academic Editor: Jianwei Cheng

Copyright (c) 2021 Qiang Sun et al. This is an open access article distributed under the Creative Commons Attribution License, which permits unrestricted use, distribution, and reproduction in any medium, provided the original work is properly cited.

Solid waste backfill mining can effectively deal with gangue and other mining wastes, as well as control the movement and damage of rock strata. In this paper, the RFPA ${ }^{2 \mathrm{D}}$ rock failure process analysis software is used to study the fracture evolution and seepage response mechanism of the key aquiclude strata (KAS) under the conditions of different structural characteristics, interlayer rock thickness, and backfilling ratios in backfill mining. The simulation results show that, in backfill mining, soft rock plays a crucial role in the fracture repair of KAS with different structural characteristics. An increase in the KAS thickness from 15 to $35 \mathrm{~m}$ is shown to results in a continuously improved repair of KAS fractures. At the advancing distance of the working face of $50 \sim 100 \mathrm{~m}$ and the KAS thickness of $35 \mathrm{~m}$, the minimum vertical seepage velocity of $(0.06-0.78) \times 10^{-2} \mathrm{~m} / \mathrm{s}$ is reached. An increase in the backfilling ratio from 45 to $80 \%$ improves the control effect on the overlying strata. A case study of backfill mining in the Wugou Coal Mine located in the Anhui Province of China was conducted. At the goaf backfilling ratio of $80 \%$, the composite KAS's good control effect was achieved, which minimized seepage and avoided the water in rush phenomena. The above engineering application ensured the safe backfill mining of coal resources.

\section{Introduction}

The global demand for green energy is related to the inevitable exhaustion of fossil fuels and increasing concern about the environment and air quality. China has also increased the direct use of renewables via wind and bioenergy for industry needs, solar thermal energy for heating, and biofuels for transport. However, the current share of coal in China's total power generation still exceeds $50 \%$ and is not expected to drop below $40 \%$ by 2040 [1]. China's demand for coal resources was about 3.55 billion tons in 2019, and further coal production envisages this sector restructuring, making most mines profitable and closing the least efficient mines [2].

Safe underground coal mining became increasingly challenging due to the complex hydrogeological conditions of numerous coal mines in China [3]. In the last seventy years, many coal resources under water bodies have been successfully mined out. However, most mining areas adopted waterproof coal pillar reservation methods, strip mining, thickness limiting mining, and drainage pressure reduction for coal mining under water bodies, which resulted in a large-scale waste of coal and water resources [4-6]. According to statistics, in Northern and Eastern China, mining coal-bearing strata, which are affected by confined aquifers, has sterilized over five billion tons of coal in waterproof coal pillars. In the past 20 years, there have been more than 800 water inrush disasters in mines, causing more than 4,000 deaths $[7,8]$. These facts necessitate selecting a reasonable mining method for areas with aquifers, improving the coal recovery rate, ensuring production safety, and protecting water resources. 
As a typical example of green mining technology, solid backfill mining (SBM) has been successfully applied to coal mining below large rivers, aquifers, and other water bodies $[9,10]$. The theoretical research and field measurement results related to this technology show that under the coupling effect of the backfill body and surrounding rock, the development height of the water-conducting fractured zone (HWFZ) in the overlying strata can be limited, and the surrounding rock fractures readily compacted and closed. This greatly reduces the water inrush risk, improves the coal recovery rate, and protects water resources. SBM technology has become one of the important measures to realize water conservation mining, groundwater environment protection, and premining water table maintenance in green mines $[11,12]$. However, theoretical research efforts of the global scientific community on safe mining, such as caving and backfill mining, under surface water bodies and aquifers, are mostly focused on controlling the development height of overburden water diversion fracture zone, HWFZ, which should not reach the water body and aquifer $[13,14]$. The seepage and water inrush problem, influenced by the lithologic structure and the water isolation performance of each coal measure strata, has received much less attention.

To this end, the fracture evolution and seepage response mechanism of the key aquiclude strata (KAS) under conditions of different structural parameters, geologic characteristics, and backfilling ratios (backfilling materials' compaction bearing ratio in goaf) [15] in SBM mining are numerically simulated in this study using the $\mathrm{RFPA}^{2 \mathrm{D}}$ rock failure process analysis software. This paper investigates the effect of different geological structural parameters and multilayer characteristics of KAS on repairing damage caused by mining to overlying strata and the related vertical seepage velocity. Field measurements verify the simulation results obtained. The positive control effect of the composite KAS on the mitigation of excessive seepage and water inrush is demonstrated. The adopted method ensured safety for the SBM method and provided a reference for engineering applications under similar conditions.

\section{Numerical Simulation Model and Scheme}

2.1. Numerical Simulation Model. The rock failure process analysis (RFPA) is mainly used for numerical simulations of rock fracture progression. RFPA is a numerical analysis tool and calculation method based on finite element stress analysis and modeled statistical damage interpretation. RFPA fully considers the characteristics of nonlinearity, nonuniformity, and anisotropy in progressive fracturing and the potential failure of rock. In this software, the heterogeneity of rock material is fully considered, and complex macrononlinear mechanical problems are transformed into simple continuous media problems. At the same time, the effect and change of the coupling of stress, damage, and seepage resulting from the interaction between existing and newly initiated cracks are considered [16-20]. Therefore, the mining rock mass's failure principle and failure process align with the actual site situation. The RFPA mainly includes static, dynamic, combined dynamic and static, seepage, temperature, and multifield coupling analyses [21-24]. The basic principle of the RFPA ${ }^{2 \mathrm{D}}$ flow coupling module is based on the following assumptions.

(a) The seepage process in rock satisfies the Biot consolidation theory:

Equilibrium equation:

$$
\frac{\partial \sigma_{i j}}{\partial x_{i j}}+\rho X_{j}=0(i, j=1,2,3) .
$$

Geometric equation:

$$
\varepsilon_{i j}=\frac{1}{2}\left(\mu_{i, j}+\mu_{j, i}\right) \varepsilon_{v}=\varepsilon_{11}+\varepsilon_{22}+\varepsilon_{33} .
$$

Constitutive equation:

$$
\sigma_{i j}=\sigma_{i j}-\alpha p \delta_{i j}=\lambda \sigma_{i j} \varepsilon_{v}+2 G \varepsilon_{i j}
$$

Seepage equation:

$$
K \nabla^{2} p=\frac{1}{Q} \frac{\partial p}{\partial t}-\alpha \frac{\partial \varepsilon_{v}}{\partial t}
$$

where $\rho$ is density; $\sigma_{i j}$ is stress tensor; $\varepsilon_{v}$ is volume strain; $\delta$ is Kronecker constant; $Q$ is Biot constant; $G$ is shear modulus; $\lambda$ is Lame coefficient; and $\nabla^{2}$ is Laplace operator.

(b) The mesoelement in rock is elastic and brittle and has a certain residual strength, while its mechanical behavior conforms to the elastic damage theory. The maximum tensile strength and the MohrCoulomb criteria are taken as the threshold conditions of damage; that is, when the element satisfies both the maximum tensile stress-strain and the Mohr-Coulomb criteria, the initial damage occurs

(c) The rock structure is nonuniform. The damage parameters of the mesounit are assigned according to the Weibull distribution. The nonuniform Weibull distribution function and integral are derived as follows:

$$
\begin{gathered}
\varphi(E)=\frac{n}{E_{0}}\left(\frac{E}{E_{0}}\right)^{n-1} e^{-\left(E / E_{0}\right) n} \\
\varphi(E)=\int_{0}^{e} \varphi(x) d x=\int_{0}^{e}\left\{\frac{n}{E_{0}}\left(\frac{E}{E_{0}}\right)^{n-1} e^{-\left(E / E_{0}\right) n}\right\} d x=1-e^{-\left(E / E_{0}\right) n},
\end{gathered}
$$

where $E$ and $E_{0}$ are the elastic modulus and the statistically average value of the mesounit of the rock medium, respectively, $n$ is the homogeneity (smaller values of $n$ correspond to more dispersed material properties), and $\varphi(E)$ is the statistical distribution density. 
TABLE 1: The model geometry, physical, and mechanical parameters of overlying strata.

\begin{tabular}{|c|c|c|c|c|c|c|c|}
\hline Lithology & $\begin{array}{c}\text { Elastic modulus, } \\
\mathrm{GPa}\end{array}$ & $\begin{array}{l}\text { Poisson's } \\
\text { ratio }\end{array}$ & $\begin{array}{c}\text { Cohesion, } \\
\mathrm{MPa}\end{array}$ & $\begin{array}{l}\text { Internal friction } \\
\text { angle, }\end{array}$ & $\begin{array}{l}\text { Density, } \\
\mathrm{kN} \cdot \mathrm{m}^{-3}\end{array}$ & $\begin{array}{l}\text { Permeability coefficient, } \times 10^{-} \\
{ }_{7} \mathrm{~m} \cdot \mathrm{s}^{-1}\end{array}$ & Porosity \\
\hline $\begin{array}{l}\text { Overlying } \\
\text { strata }\end{array}$ & 8.5 & 0.28 & 4.5 & 32.0 & 24.0 & 0.20 & 0.10 \\
\hline Aquifer & 22.0 & 0.25 & 8.0 & 34.0 & 26.0 & 11.57 & 0.25 \\
\hline Mudstone & 6.7 & 0.32 & 2.7 & 24.0 & 22.0 & 0.05 & 0.01 \\
\hline Siltstone & 16.3 & 0.28 & 8. 8 & 35.9 & 24.0 & 0.12 & 0.12 \\
\hline $\begin{array}{l}\text { Fine } \\
\text { sandstone }\end{array}$ & 20.1 & 0.26 & 14.2 & 36.7 & 26.0 & 0.14 & 0.15 \\
\hline $\begin{array}{l}\text { Immediate } \\
\text { roof }\end{array}$ & 7.2 & 0.32 & 3.5 & 28.0 & 22.0 & 0.08 & 0.05 \\
\hline Coal seam & 5.5 & 0.30 & 2.5 & 26.0 & 14.0 & 0.30 & 0.20 \\
\hline Floor & 25.0 & 0.25 & 12.0 & 32.0 & 25.0 & 0.15 & 0.02 \\
\hline
\end{tabular}

(d) The relationship between permeability and stressstrain function is satisfied in the elastic state of the mesounit, and the permeability increases obviously after damage and fracture. The equation linking the stress $\sigma_{i j}$ and permeability coefficient $K$ of the model has the following form:

$$
K=\xi K_{0} \exp \left[-\beta\left(\frac{\sigma_{i j}}{3}-\alpha p\right)\right]
$$

where $K$ and $K_{0}$ are the permeability coefficient and its initial value, respectively; $p$ is the pore water pressure; $\xi$ is the sudden jump rate of permeability coefficient, $\alpha$ is the pore water pressure coefficient, and $\beta$ is the stress-sensitive factor.

The effective stress and damage variables influence element's permeability variation, while its permeability also affects the stress distribution through the water pressure variation. Thus, the element stress and seepage fields are coupled. Based on the particular geological conditions of the Wugou Coal Mine mining face located in the north of Anhui Province, China, a basic 2D mechanical simplified model with length $\times$ height of $180 \mathrm{~m} \times 80 \mathrm{~m}$ was established along the coal seam strike. The numerical simulation was selected to study the fracture evolution characteristics and seepage distribution law under the different influencing factors of the structural geology parameters, interlayer rock thickness, and KAS's backfilling ratios. The horizontal and vertical displacement constraints were applied to both sides and the bottom of the model. The model's upper surface applied the equivalent crustal stress uniform load of $5.75 \mathrm{MPa}$ (corresponding to a buried depth of $300 \mathrm{~m}$ ). The thickness of the model aquifer was $15 \mathrm{~m}$. The water head boundary of $200 \mathrm{~m}$ was applied to both sides of the aquifer, while the remaining boundary was set as a water separation boundary. The mining area boundary was set as a zero-water head boundary. The numerical model was subdivided into 22,500 units in total. The revised Mohr-Coulomb model was used for the rock material within the framework of the plane strain simplified model. Physical and mechanical parameters, as well as seepage characteristics of the rock, are listed in Table 1.

2.2. Numerical Simulation Scheme. The analysis revealed that structural parameters, interlayer rock thickness, and backfilling ratios in the goaf were the key factors influencing the KAS control effect in the backfill mining under the aquifer. Using the RFPA ${ }^{2 \mathrm{D}}$ software, the effect of the above three influencing factors on the KAS water-holding performance in the backfill mining control was analyzed. A total of three schemes and ten groups of numerical models were designed (as shown in Table 2).

2.2.1. Scheme 1. Under the condition of backfilling ratio $65 \%$ and distance of $20 \mathrm{~m}$ between the coal seam and aquifer, the fracture evolution characteristics and seepage response of the KAS with four different structural features, namely, single-layer soft rock (mudstone), single-layer hard rock (fine sandstone), double-layer soft/hard composite KAS (mudstone and fine sandstone), and four-layer soft/hard composite KAS (mudstone, siltstone, mudstone, and fine sandstone), were analyzed. The distribution patterns used in the numerical simulation of the respective schemes are depicted in Figure 1.

2.3. Scheme 2. The mining geological conditions of the working face in the Wugou Coal Mine were combined with the three-layer composite KAS's occurrence characteristics composed of mudstone, siltstone, and fine sandstone. Fractures of the composite KAS were analyzed under the condition that the working face was 15,25 , and $35 \mathrm{~m}$ below the aquifer, and the backfilling ratio was $65 \%$. For scheme 2, the evolution characteristics and seepage response distributions were derived via the numerical simulation for the respective schemes depicted in Figures 2(a), 2(c), and 2(d).

2.3.1. Scheme 3. Scheme 3 was used to analyze the fracture evolution characteristics and seepage distribution rules of the three-layer composite KAS composed of mudstone, siltstone, and fine sandstone during the mining process. The working face was $21.8 \mathrm{~m}$ below the overlying aquifer, while the goaf backfilling ratios were $45 \%, 65 \%$, and $80 \%$, 
TABLE 2: Numerical simulation schemes and parameters.

\begin{tabular}{|c|c|c|c|}
\hline Scheme no. & Lithology and parameters of KAS & Backfilling ratio, $\%$ & Interlayer rock thickness, $\mathrm{m}$ \\
\hline \multirow{4}{*}{1} & Mudstone $18 \mathrm{~m}$ & \multirow{4}{*}{65} & \multirow{4}{*}{20} \\
\hline & Fine sandstone $16 \mathrm{~m}$ & & \\
\hline & Mudstone $9 \mathrm{~m}$, fine sandstone $9 \mathrm{~m}$ & & \\
\hline & Mudstone $5 \mathrm{~m}$, siltstone $5 \mathrm{~m}$, mudstone $5 \mathrm{~m}$, fine sandstone $5 \mathrm{~m}$ & & \\
\hline \multirow{3}{*}{2} & Mudstone $5.8 \mathrm{~m}$, siltstone $1.3 \mathrm{~m}$, fine sandstone $5.4 \mathrm{~m}$ & \multirow{3}{*}{65} & 15 \\
\hline & Mudstone $10.5 \mathrm{~m}$, siltstone $4.4 \mathrm{~m}$, fine sandstone $7.6 \mathrm{~m}$ & & 25 \\
\hline & Mudstone $15.2 \mathrm{~m}$, siltstone $7.5 \mathrm{~m}$, fine sandstone $9.8 \mathrm{~m}$ & & 35 \\
\hline \multirow{3}{*}{3} & Mudstone $8.8 \mathrm{~m}$, siltstone $3.4 \mathrm{~m}$, fine sandstone $7.1 \mathrm{~m}$ & 45 & \multirow{3}{*}{21.8} \\
\hline & Mudstone $8.8 \mathrm{~m}$, siltstone $3.4 \mathrm{~m}$, fine sandstone $7.1 \mathrm{~m}$ & 65 & \\
\hline & Mudstone $8.8 \mathrm{~m}$, siltstone $3.4 \mathrm{~m}$, fine sandstone $7.1 \mathrm{~m}$ & 80 & \\
\hline
\end{tabular}

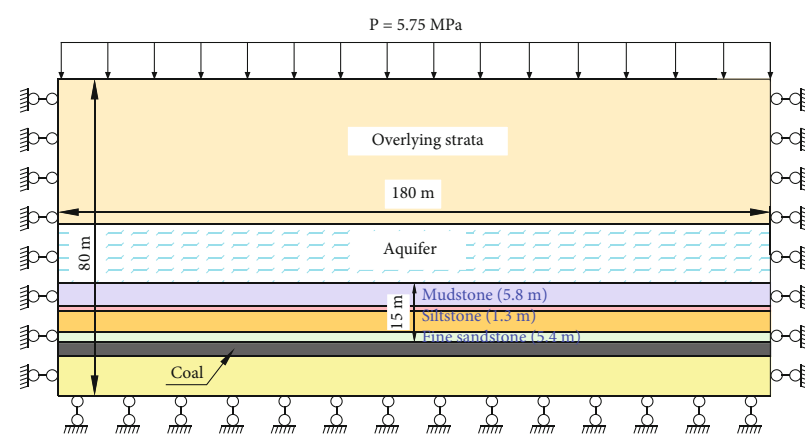

(a)

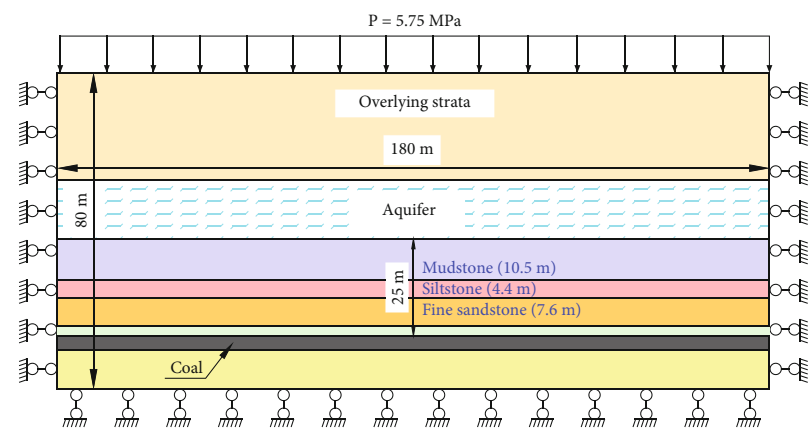

(c)

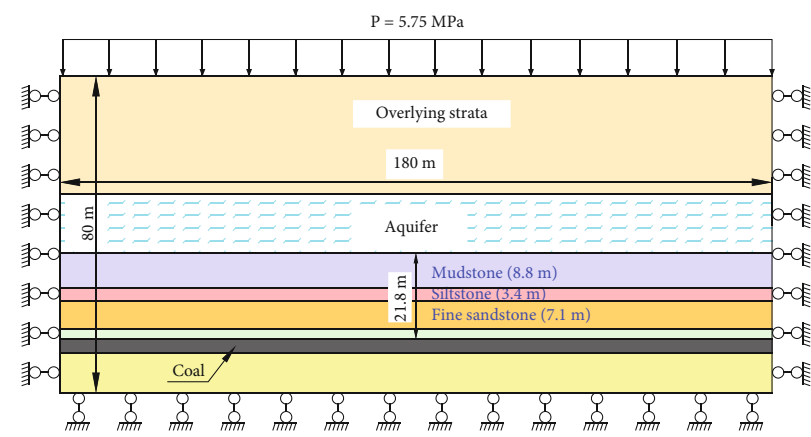

(b)

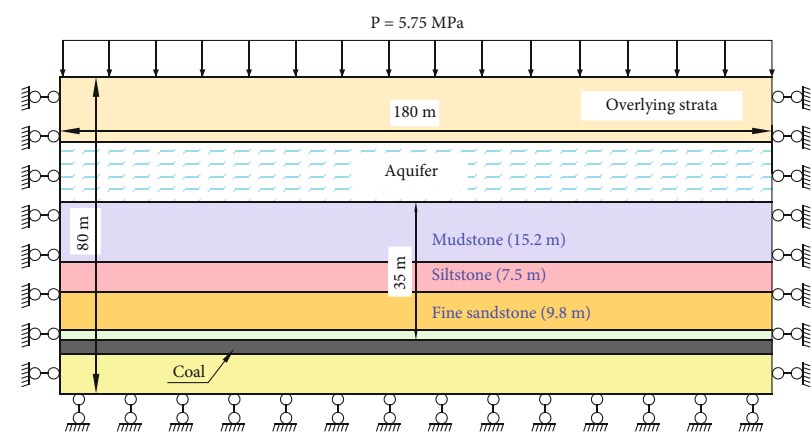

(d)

FIGURE 1: Numerical simulation model of KAS with different structural features: (a) single-layer soft KAS; (b) single-layer hard KAS; (c) double-layer soft/hard composite KAS; (d) four-layer soft/hard composite KAS.

respectively. The distribution pattern used in the numerical simulation is depicted in Figure 2(b).

\section{Results and Discussion}

According to the above schemes, the fracture evolution characteristics and seepage response patterns of the overlying rock in SBM with the mining height of $3.5 \mathrm{~m}$, mining depth of $300 \mathrm{~m}$, and the backfilling ratio of $65 \%$ were analyzed for different structural characteristics of single-layer soft rock, single-layer hard rock, and double- and four-layer soft/hard composites. For the working face advance of $100 \mathrm{~m}$ and the backfilling ratio of $65 \%$, the cloud chart of the evolution of the overlying rock fracture and the seepage vector's distribu- tion pattern for the above structural features were plotted (as shown in Figure 3).

The simulation results show that the fracture evolution characteristics of the KAS with the structural characteristics of a single-layer soft rock are relatively low. In contrast, the evolution process involves fracture initiation, development, compaction, and closure. This kind of rock structure is readily subjected to fracture compaction and closure under the coupling action of the backfill materials, overburden stress, water pressure, and good repair characteristics. Under the structural characteristics of single-layer hard rock, KAS's initial fracture development is relatively slow. With a continuous increase in the coal face's advance distance, when the first collapse and the periodic collapse step distance are 


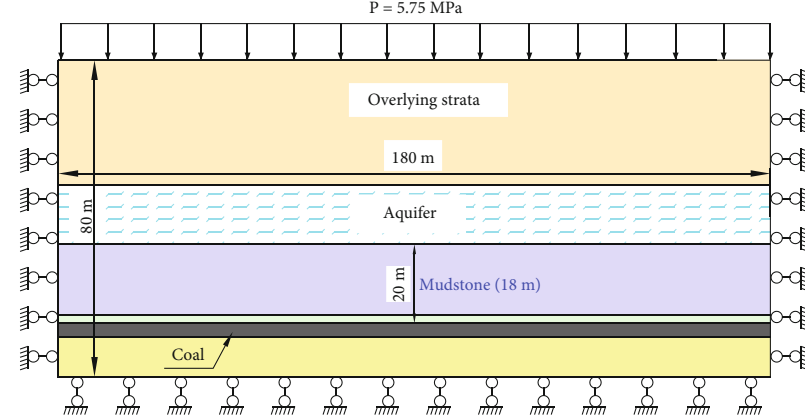

(a)

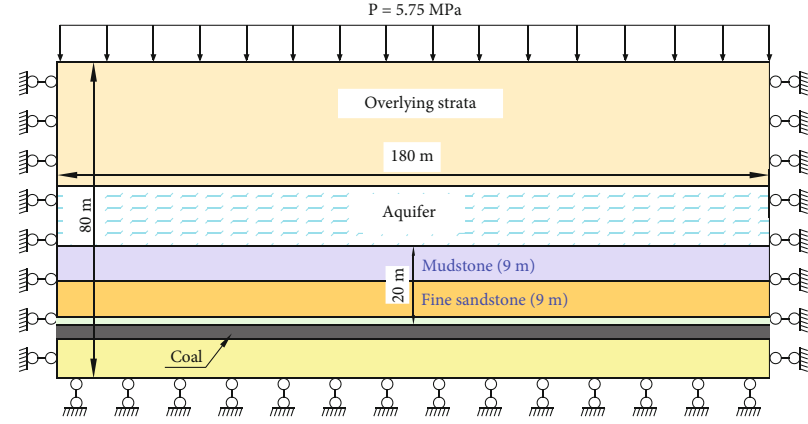

(c)

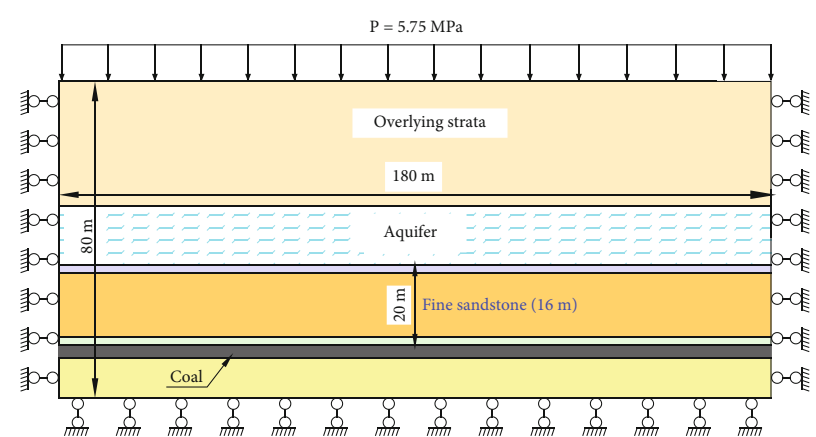

(b)

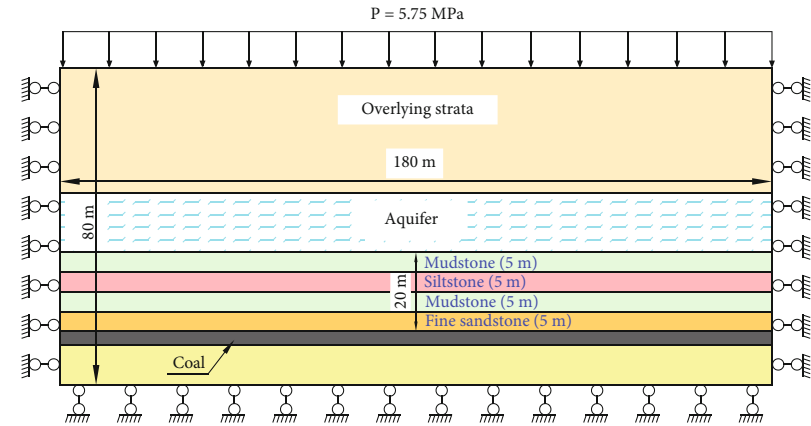

(d)

Figure 2: Numerical model with different interlayer rock thickness: (a) $15 \mathrm{~m}$; (b) $21.8 \mathrm{~m}$; (c) $25 \mathrm{~m}$; (d) $35 \mathrm{~m}$.

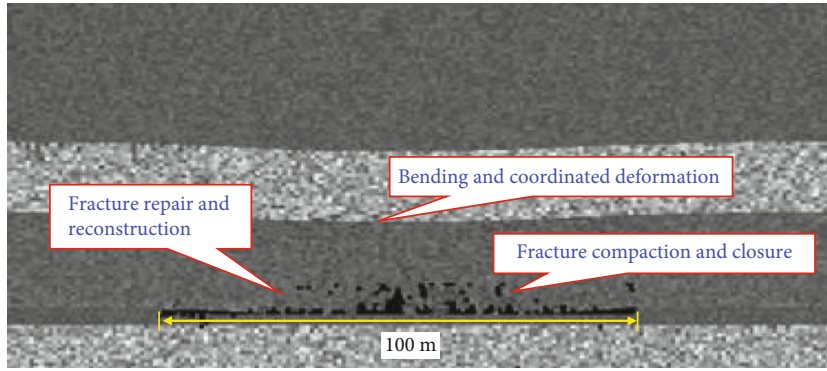

(a)

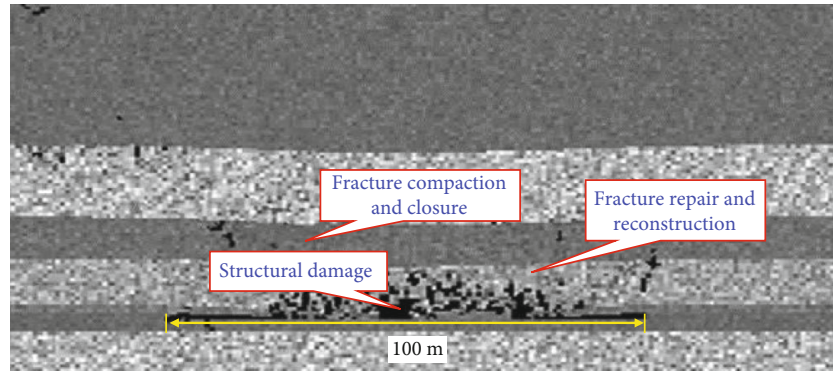

(c)

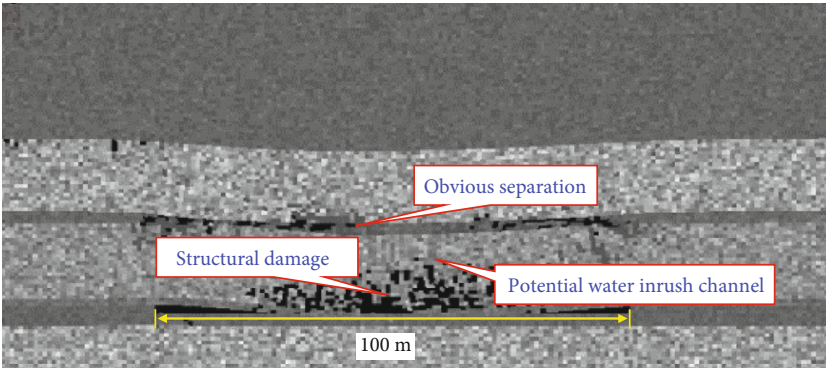

(b)

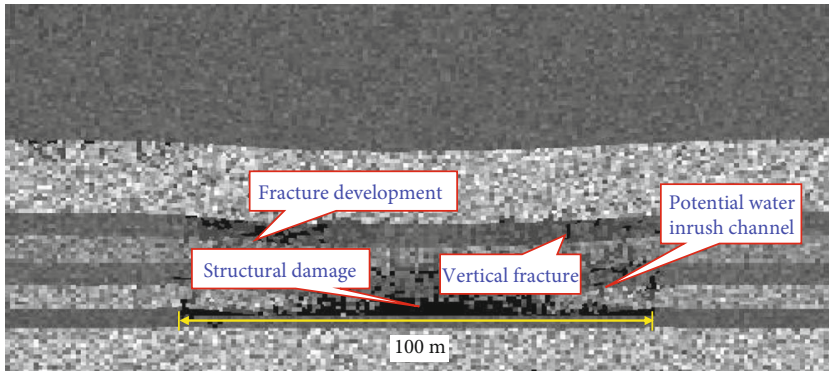

(d)

FIGURE 3: Fracture evolution and seepage response of different overlying strata structures: (a) single-layer soft KAS; (b) single-layer hard KAS; (c) double-layer composite KAS; (d) four-layer composite KAS.

reached, the rock stratum breaks suddenly and forms a fractured water inrush channel. After the fracture development and expansion, the compaction and closure of joints are unlikely, which leads to an extreme risk of a water inrush disaster. Therefore, the surrounding rock's stress state before fracture and damage should be controlled for this kind of
KAS. Under the backfill materials' influence, a hinged supporting structure is readily formed after the hard rock's damage in the lower part of double- and four-layer soft/hard composites. This hinged fracture can be repaired to different degrees under the compaction of the soft upper rock. Noteworthy is that the overall control effect of the double-layer 


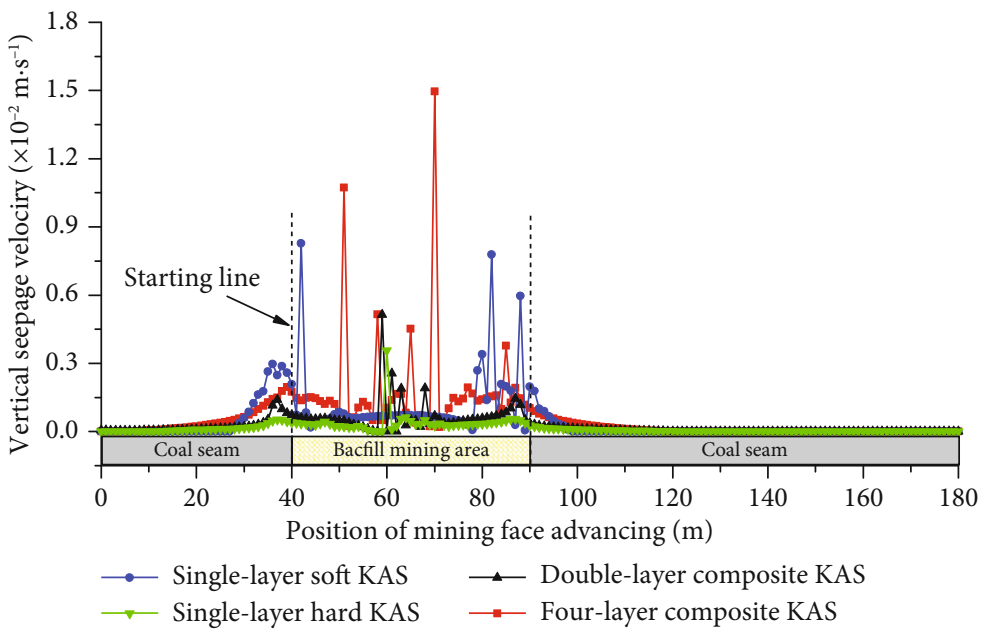

(a)

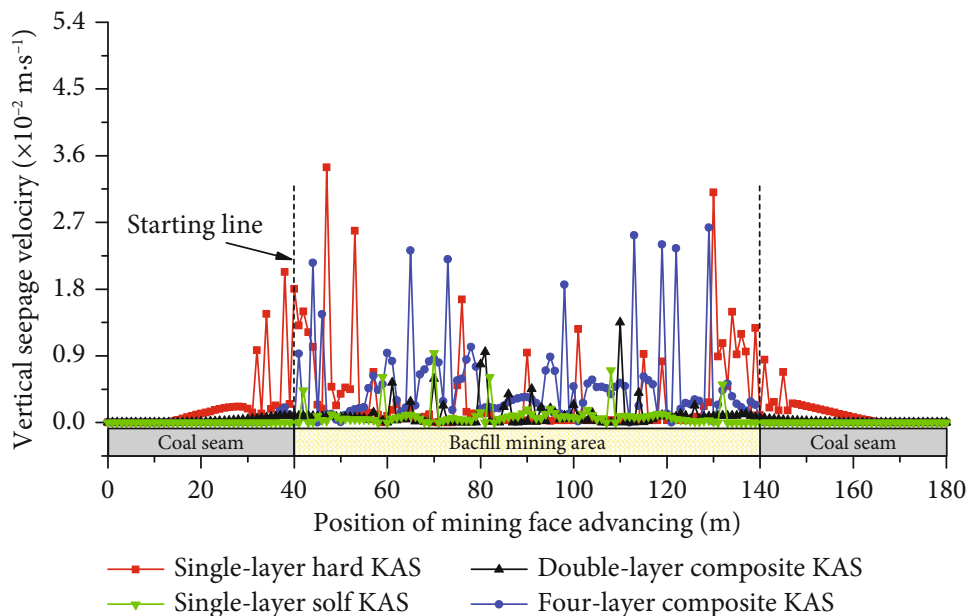

(b)

FIGURE 4: Vertical seepage flow distribution of KAS with different structural features: (a) advancing distance 50 m; (b) advancing distance $100 \mathrm{~m}$.

soft/hard composite KAS is better than that of four-layer one, while the fracture development degree in both cases is relatively mild.

According to different structural characteristics, the vertical seepage velocity distribution curves in the middle of the KAS along the advancing direction of the working face were constructed, for advancing distances of 50 and $100 \mathrm{~m}$, as shown in Figures 4(a) and 4(b), respectively.

It can be seen in Figure 4 that under different structural characteristics, the KAS seepage flow in the SBM water separation increases gradually with the continuous advance of the working face. The seepage flow's peak value is mainly distributed in the rear of the goaf, in front of the working face, and in the middle of the stope. At the mining distance of the working face of 50 100 m, under different structural characteristics of single-layer soft rock, single-layer hard rock, and double- and four-layer soft/hard composite, the variation ranges of the peak value of seepage velocity of the key layer are $(0.83 \sim 0.94) \times 10^{-2},(0.36 \sim 3.40) \times 10^{-2},(0.51$ $\sim 1.35) \times 10^{-2}$, and $(1.49 \sim 2.53) \times 10^{-2} \mathrm{~m} / \mathrm{s}$, respectively.
Under different structural characteristics, the KAS variation in peak seepage flow is 1.13-2.63 times under the rock layering sequences of single-layer soft rock and double-layer soft/hard composite structures, which is relatively smooth as a whole and has a good control effect. In contrast, the variation in peak seepage flow in the key layer of water separation is 1.69-9.50 times under the rock layering sequences of single-layer hard rock and four-layer soft/hard composite structures, which is relatively large as a whole and easy to cause water inrush. Under the condition of the same backfilling ratio, the SBM control effect is closely related to the structural characteristics of the KAS. The structural hard rock mainly plays a mechanical load-bearing role, making self-repair after breaking quite problematic and promoting damage to this rock layer. The occurrence characteristics of the weak rock layer result in an obvious improvement in fracture compaction and repair. When the hard rock is damaged, the adjacent soft rock is compacted to close the potential water inrush fissures and form the water-resisting rock stratum, achieving the water-resisting layer's repair effect. 


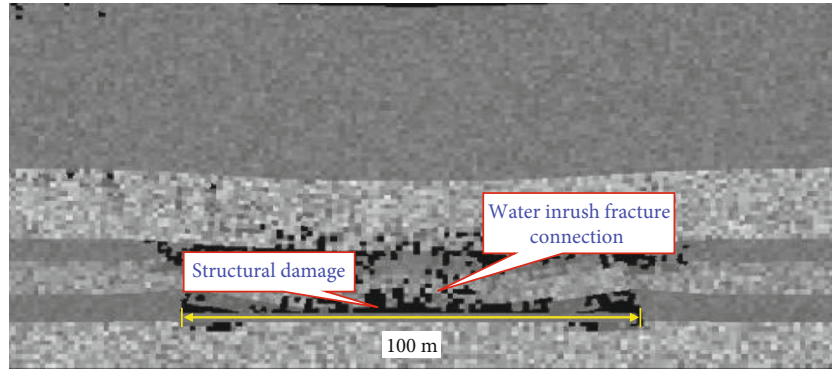

(a)

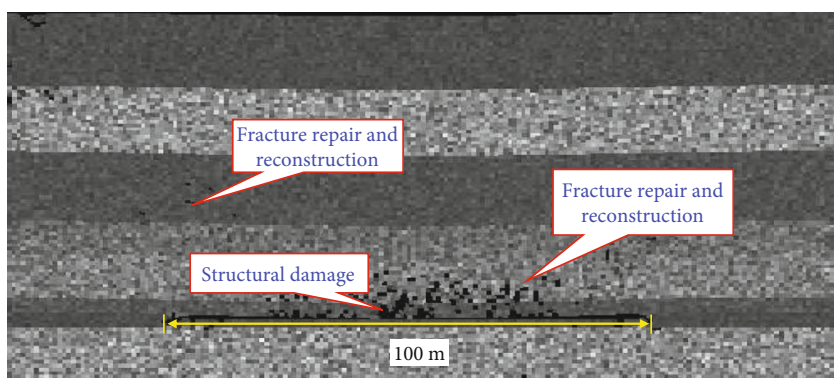

(c)

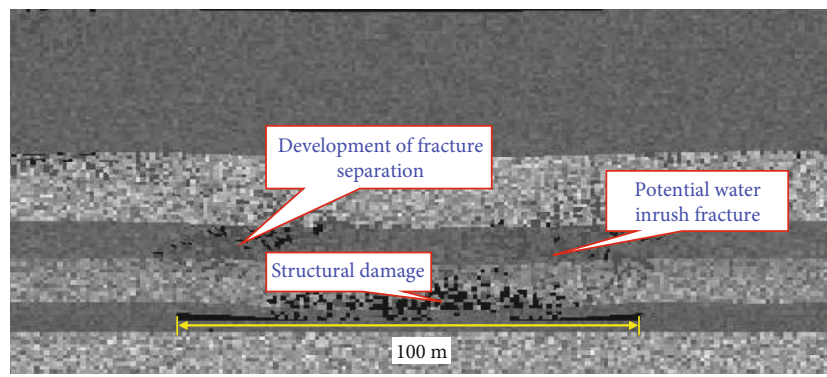

(e)

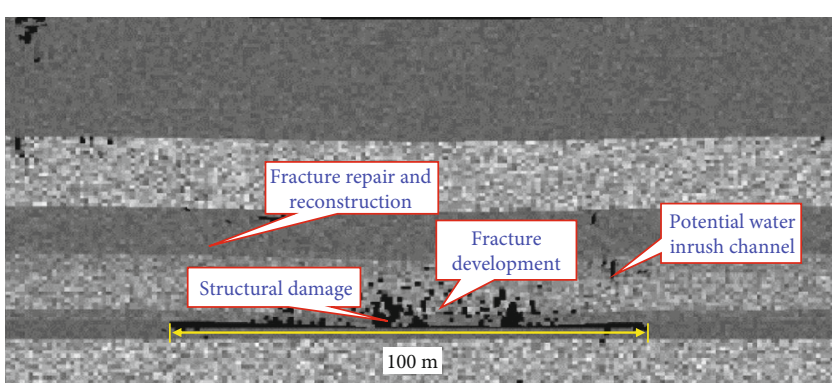

(b)

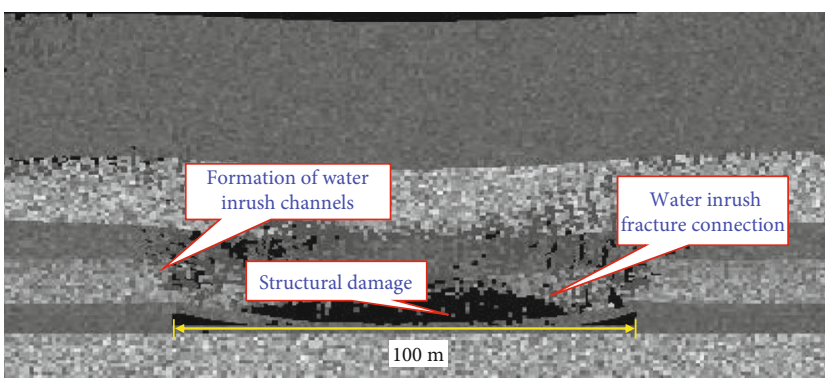

(d)

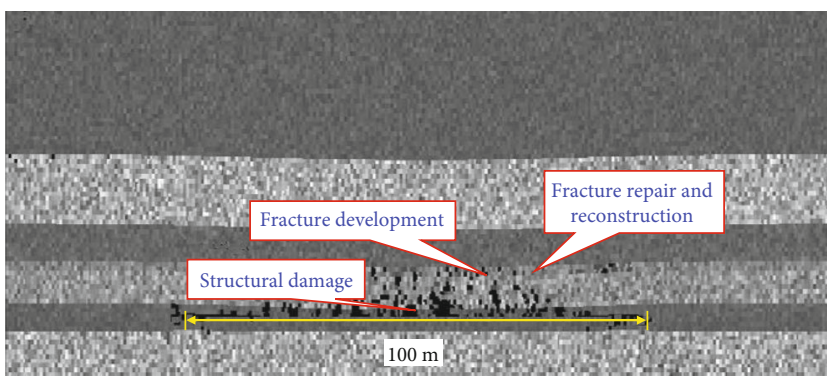

(f)

FIGURE 5: Fracture evolution characteristics and seepage response of overlying strata with different interlayer rock thickness and backfilling ratios: (a) $15 \mathrm{~m}$; (b) $25 \mathrm{~m}$; (c) $35 \mathrm{~m}$; (d) $45 \%$; (e) 65\%; (f) $80 \%$.

The overlying strata's fracture evolution characteristics and seepage response were also simulated for the mining height of $3.5 \mathrm{~m}$, mining depth below ground of $300 \mathrm{~m}$, backfilling ratio of $65 \%$, and rock thicknesses of 15,25 , and $35 \mathrm{~m}$ between the working face and aquifer. At a backfilling ratio of $65 \%$ and the working face advance of $100 \mathrm{~m}$, the cloud charts of the evolution of the overlying rock fracture under the influence of three different layer thicknesses were constructed (as shown in Figures 5(a)-5(c)). At the goaf backfilling ratio of 45,65 , and $80 \%$, the overlying strata's fracture evolution characteristics and seepage response were further simulated. At the interlayer rock thickness of $21.8 \mathrm{~m}$ and the advancing distance of the working face of $100 \mathrm{~m}$, the cloud chart of fracture evolution of overburden under the influence of different backfilling ratios was constructed (as shown in Figures 5(d)-5(f)).

It can be seen in Figures 5(a)-5(c) that when the rock thickness between the mining void and the aquifer is $15 \mathrm{~m}$, the overall thickness of the KAS is relatively thin. With the continuous advancement of the backfill working face, the rock stratum is broken, and the mining-induced fractures expand to connect to the aquifer, and then, the water inrush fracture channel is formed. With an increasing rock thick- ness between the mining void and the aquifer, the overall performance of the composite KAS improves and tends to be beneficial. After backfilling the mining void (Figures 5(d)-5(f)), the lower fine sandstone and siltstone are damaged. However, they still maintain some mechanical load-bearing capacity. Under the soft upper rock action, the mining fractures are readily compacted and closed, and the rock mass has some integrity based on visual inspection of the number of fractures. Under the influence of the backfilling body's effective bearing capacity, with the continuous increase of the KAS thickness from 15 to $35 \mathrm{~m}$, the overall control effect of the KAS in the backfill mining is significantly improved.

It can be seen in Figures 5(d)-5(f) that at a backfilling ratio of $45 \%$, the overall damage of overburden is relatively severe. When the working face is mined for $50 \mathrm{~m}$, the lower fine sandstone has been damaged. When the working face is mined $100 \mathrm{~m}$ in advance of the backfill, a large area of fracture and damage occurs in the composite KAS, and mininginduced fractures penetrate the aquifer, causing a water inrush disaster. Overall mining-induced damage to the KAS is reduced at a backfilling ratio of $65 \%$ and a $100 \mathrm{~m}$ mining advance. After mining the working face, a 


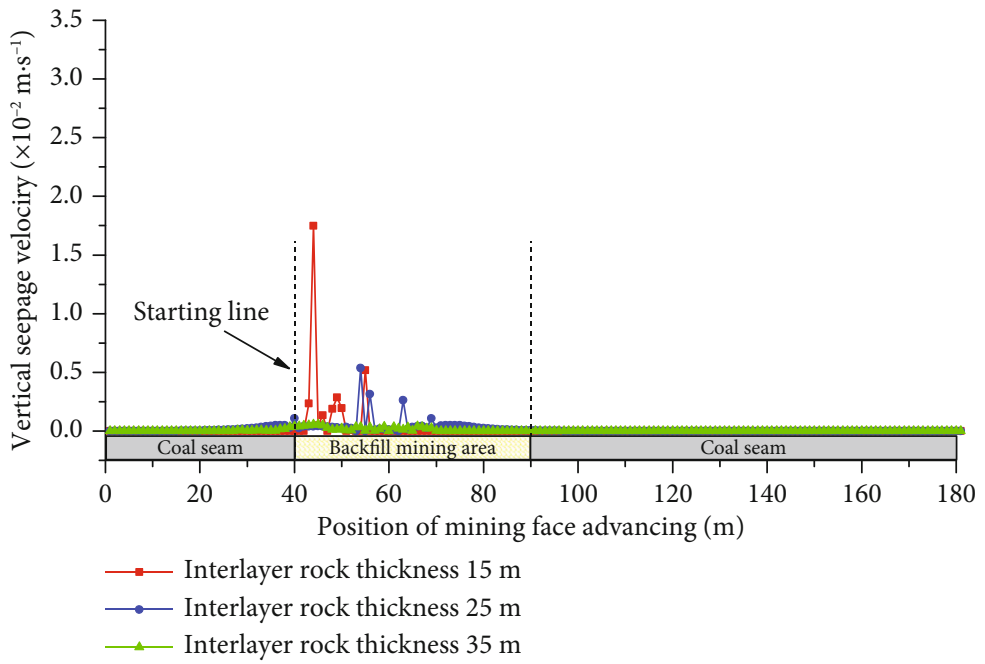

(a)

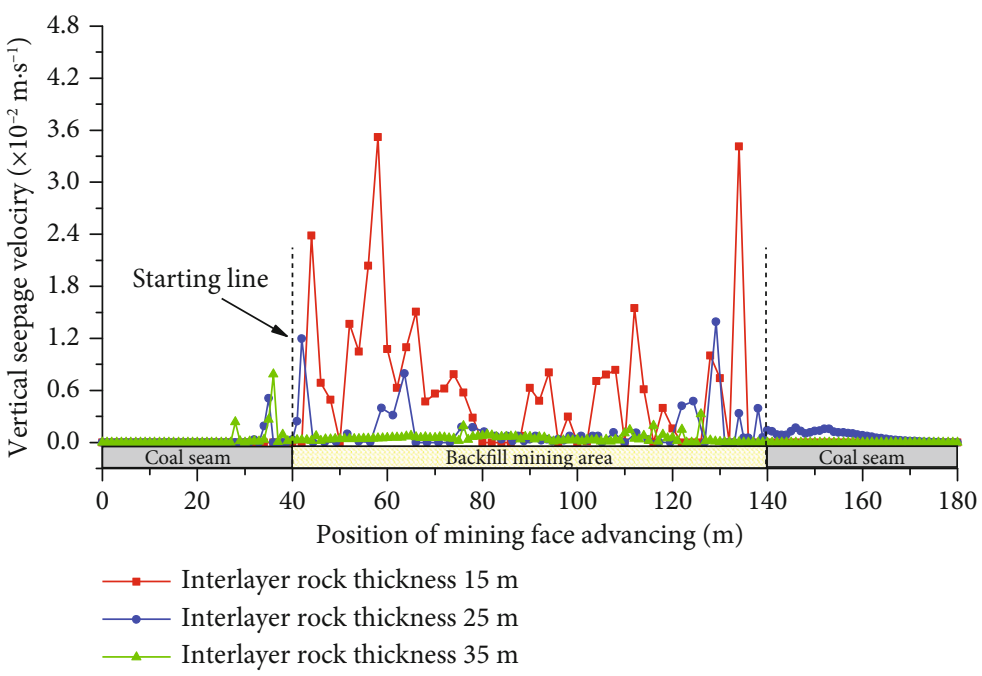

(b)

Figure 6: Vertical seepage flow distribution of KAS with different interlayer rock thickness: (a) advancing distance 50 m; (b) advancing distance $100 \mathrm{~m}$.

mechanical bearing structure can be formed after the mining damage of the lower fine sandstone and siltstone. Compaction of the upper mudstone layer in the KAS plays an important role in maintaining water separation and seepage prevention. At a backfilling ratio of $80 \%$, the fine sandstone and siltstone in the lower part of the composite KAS remain relatively intact after mining. The overall development of mining-induced rock fractures is restrained, while the soft mudstone layer in the upper part is unaffected by mining damage. Thus, the KAS can maintain the original water separation performance.

According to the characteristics of different layers, the vertical seepage velocity distribution curve in the middle of the KAS along the working face's advancing direction is shown in Figure 6. Corresponding to different backfilling ratios, the vertical seepage velocity distribution curve of the middle part of the KAS along the working face's advancing direction is shown in Figure 7.
It can be seen in Figure 6 that under the influence of different interlayer rock thicknesses, the seepage flow in the KAS increases gradually with the continuous advance of the working face. The peak value of seepage flow is also mainly distributed in the rear of the goaf, the front of the working face, and the middle of the stope. When the working face's advancing distance was $50 \sim 100 \mathrm{~m}$, the variation ranges of the peak value of the seepage velocity of KAS were $(1.75 \sim 3.52) \times 10^{-2},(0.54 \sim 1.55) \times 10^{-2}$, and $(0.06 \sim 0.78)$ $\times 10^{-2} \mathrm{~m} / \mathrm{s}$ for the working face thickness of 15,25 , and $35 \mathrm{~m}$ from the aquifer, respectively. With increase in KAS's thickness, the seepage flow peak value decreased at the same advance distance. Under the same backfill mining conditions, KAS's layer characteristics differ in the SBM control effect.

It can be seen in Figure 7 that at different backfilling ratios, the seepage flow of the KAS increases gradually with the continuous advance of the working face. The peak value of seepage flow is mainly concentrated in the fracture 


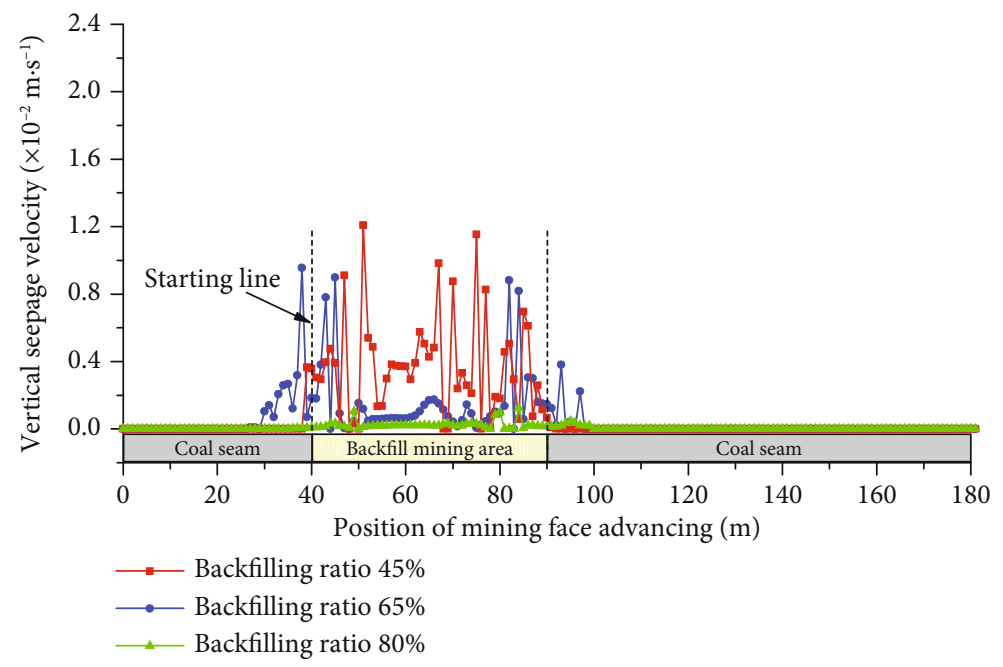

(a)

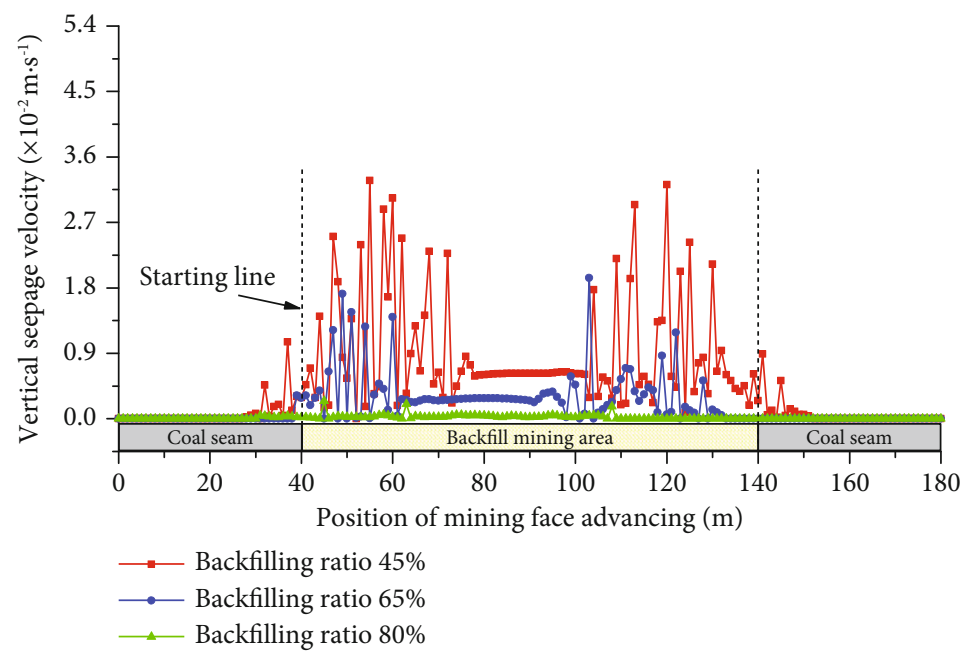

(b)

FIGURE 7: Vertical seepage flow distribution of KAS with various backfilling ratios: (a) advancing distance $50 \mathrm{~m}$; (b) advancing distance $100 \mathrm{~m}$.

development and failure position behind the goaf, in front of the working face, and in the middle of the stope. At the advancing distance of the working face of 50 100 m, the variation ranges of the peak values of the key layer's seepage velocity are $(1.21 \sim 3.28) \times 10^{-2}, 2$, and $(0.10 \sim 0.24) \times 10^{-2}$ $\mathrm{m} / \mathrm{s}$ for the backfilling ratios of 45,65 , and $80 \%$, respectively. With the continuous improvement of the filling rate, the backfilling body can effectively carry KAS's stress load, inhibiting the development and expansion of cracks. Under the joint action of the backfilling body, overlying rock, and water flow, cracks are readily compacted and bridged, which is beneficial to the KAS repair effect.

The Wugou Coal Mine with a field area of $21.74 \mathrm{~km}^{2}$ is located in the Suixi County, Anhui Province, China. The eastern mining area is located in the northeastern part of the mine field with the ground elevations $26.37 \sim 7.67 \mathrm{~m}$, which is a stable horizon and simple structure. With the strike length of $2.51 \mathrm{~km}$ and incline of $0.93 \mathrm{~km}$, the average thickness of the primary mineable coal seam is $3.5 \mathrm{~m}$. The bottom aquifer of Cenozoic thick and loose strata directly covers the outcrop of the main coal resources, which poses a serious threat to the safety of coal seam mining. Based on the simulation and theoretical assessments of the parameters related to the washing gangue material with particle size $0 \sim 50 \mathrm{~mm}$ on the ground, it was concluded that the mining starting position of the first CT101 backfilling coal face should be $21.8 \mathrm{~m}$ from the upper aquifer [25]. Considering that site's working face is dip mining and upward backfilling, a certain safety factor was applied to ensure the safe production of the first backfilling working face and improve the proficiency of the backfill mining technology. The final designed backfilling ratio was determined to be $80 \%$. The KAS control effect was measured and analyzed by the transient electromagnetic method, which is practical and easy to operate. It is widely used in fracture damage and evaluation of aquifer rock mass above the mine. With the continuous mining of the working face, within the cumulative advance distance of $90 \mathrm{~m}$ of the working face, according to 


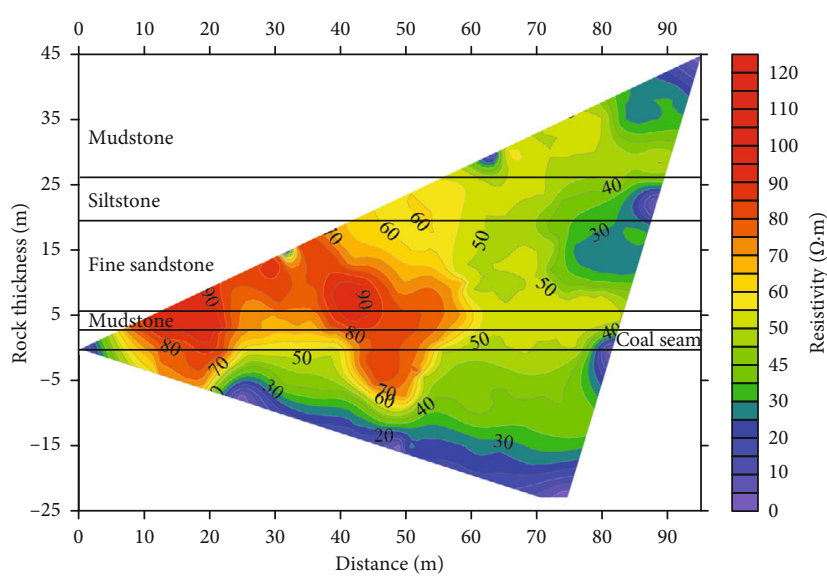

(a)

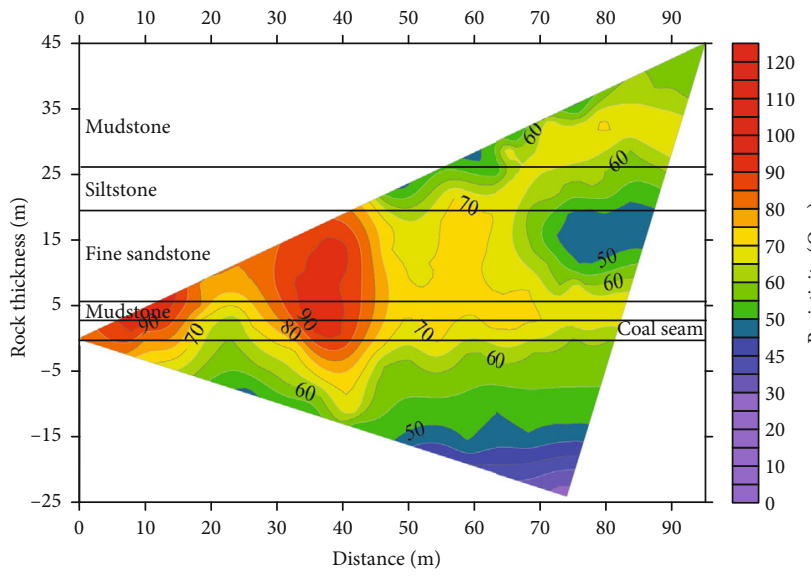

(c)

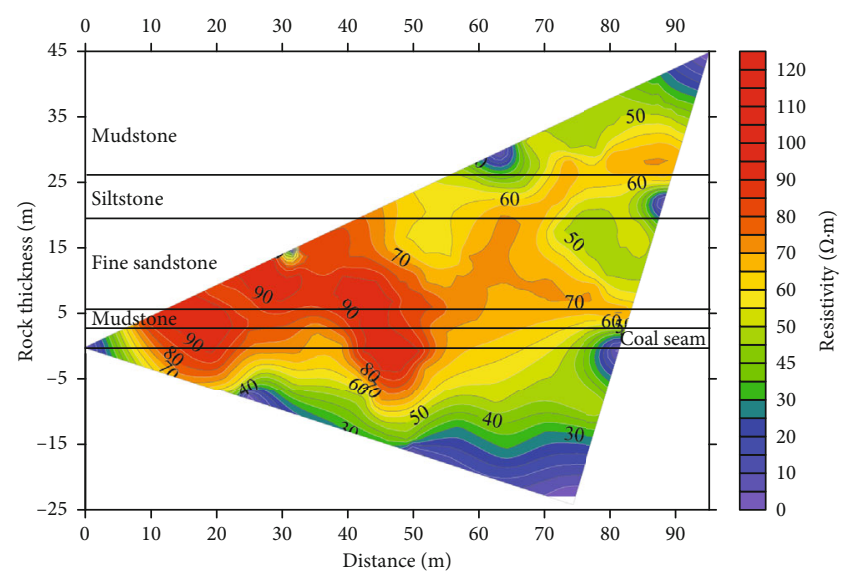

(b)

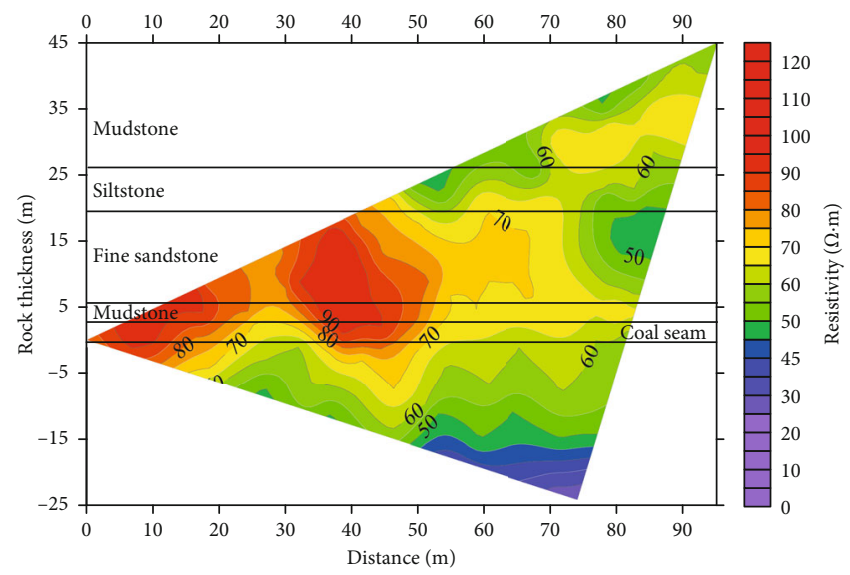

(d)

FIGURE 8: Detected resistivity profile during the backfill mining: (a) $40 \mathrm{~m}$; (b) $60 \mathrm{~m}$; (c) $70 \mathrm{~m}$; (d) $90 \mathrm{~m}$.

the field observation frequency requirements, the monitoring control area has been monitored many times, and resistivity results were obtained shown in Figure 8.

It can be seen in Figure 8 that with the mining of the working face, the roof fracture develops, and the resistivity value increases gradually. The area with an abnormal increase of resistivity is mainly within $25 \mathrm{~m}$ of the coal seam roof. The mudstone layer's resistivity in the upper part of the KAS is stable and mainly distributed within the range of $40 \sim 50 \Omega \cdot \mathrm{M}$. Using the KAS occurrence characteristics in the monitoring area and measured results, it was found that the fine sandstone and siltstone in the lower part of the KAS were partially damaged after the backfill mining. At the same time, the upper mudstone is free of fracture development. Under the coupling effect of the filling body and the overburden, the KAS is still stable. There is no water seepage and gushing in the underground working face, which shows that the control effect of backfill mining on the KAS is good, ensuring site production safety.

\section{Conclusions}

(1) Under the conditions of different structural parameters, interlayer rock thickness, and backfilling ratios, with the continuous advance of the backfill working face, the overlying rock fissures show different degrees of gradual development and evolution characteristics. Affected by this, KAS's seepage flow increases gradually with the continuous advance of the working face. The peak value of seepage flow is mainly observed in the rear of the goaf, in front of the working face, and in the middle of the stope damage location

(2) Different structural characteristics in SBM have different KAS control effects. KAS's backfilling control effect is gradually deteriorated when the structural characteristics correspond to single-layer soft rocks, double-layer soft/hard composites, four-layer soft/ hard composites, and single-layer hard rocks. With a change in the working face's layer characteristics at distances of 15,25, and $35 \mathrm{~m}$ from aquifers, the backfilling control effect of the KAS is gradually enhanced. The main factor controlling the KAS is the backfilling ratio, which determines KAS's repair effect. With an increase in the backfilling ratio, the backfill can effectively carry the overlying rock layer load. The inhibition of the development and expansion of fractures can enhance the compaction and bridging of previously formed fractures to ensure 
the recovery and improvement of KAS's water separation performance

(3) The results obtained show that after the SBM technology application in the Wugou Coal Mine in the Anhui Province of China, the mudstone layer's resistivity in the KAS was stable, and the main distribution was within the range of $40 \sim 50 \Omega \cdot \mathrm{M}$. The overall control effect of the KAS was good: there was no seepage or water gushing phenomena. This ensured the safe mining of coal resources and achieved a good engineering application effect

\section{Data Availability}

All the data used to support the findings of this study are included within the article.

\section{Conflicts of Interest}

The authors have declared that we have no financial and personal relationships with other people or organizations that can inappropriately influence our work.

\section{Acknowledgments}

The authors appreciate the financial support of this work provided by the National Natural Science Foundation of China (grant no. 52104152) and the China Postdoctoral Science Foundation (grant no. 2020M671650).

\section{References}

[1] M. G. Qian and J. L. Xu, "Discussion of several issues concerning the development of coal industry in China," Journal of Mining and Safety Engineering, vol. 23, no. 2, pp. 127-132, 2006.

[2] Q. Wu, K. Tu, Y. F. Zeng, and S. Q. Liu, "Discussion on the main problems and countermeasures for building an upgrade version of main energy(coal) industry in China," Journal of China Coal Society, vol. 44, no. 6, pp. 1625-1636, 2019.

[3] J. F. Lou, F. Q. Gao, J. H. Yang et al., "Characteristics of evolution of mining-induced stress field in the longwall panel: insights from physical modeling," International Journal of Coal Science \& Technology, vol. 8, no. 5, pp. 938-955, 2021.

[4] S. M. Wang, Q. X. Huang, L. M. Fan, Z. Y. Yang, and T. Shen, "Study on overburden aquiclude and water protection mining regionalization in the ecologically fragile area," Journal of China Coal Society, vol. 35, no. 1, pp. 7-14, 2010.

[5] Q. Wu, "Progress, problems, and prospects of prevention and control technology of mine water and reutilization in China," Journal of China Coal Society, vol. 39, no. 5, pp. 4-14, 2014.

[6] D. Z. Gu, Y. Zhang, and Z. G. Cao, "Technical progress of water resource protection and utilization by coal mining in China," Coal Science and Technology, vol. 44, no. 1, pp. 1-7, 2016.

[7] Z. Huang, Seepage Evolution in Rock Masses and Catastrophe Mechanism of Water Inrush under Liquid-Solid Coupling Effect, China University of Mining and Technology, 2016.

[8] L. M. Yin, K. Ma, J. T. Chen, Y. C. Xue, Z. Q. Wang, and B. Q. Cui, "Mechanical model on water inrush assessment related to deep mining above multiple aquifers," Mine Water and the Environment, vol. 38, no. 4, pp. 827-836, 2019.

[9] Q. Sun, J. X. Zhang, N. Zhou, and W. Y. Qi, "Roadway backfill coal mining to preserve surface water in western China," Mine Water and the Environment, vol. 37, no. 2, pp. 366-375, 2018.

[10] J. X. Zhang, Q. Sun, M. Li, and X. Zhao, "The mining-induced seepage effect and reconstruction of key aquiclude strata during backfill mining," Mine Water and the Environment, vol. 38, no. 3, pp. 590-601, 2019.

[11] D. Ma, J. X. Zhang, H. Y. Duan et al., "Reutilization of gangue wastes in underground backfilling mining: overburden aquifer protection," Chemosphere, vol. 264, article 128400, 2021.

[12] Q. X. Huang, B. N. Wei, and W. Z. Zhang, "Study of downward crack closing of clay aquiclude in shallow buried coal seam," Journal of Mining and Safety Engineering, vol. 27, no. 1, pp. 39-43, 2010.

[13] W. X. Wang, W. H. Sui, Q. H. Dong, W. W. Hu, and S. X. Gu, "Closure effect of mining-induced fractures under sand aquifers and prediction of overburden failure due to re-mining," Journal of China Coal Society, vol. 38, no. 10, pp. 1728-1734, 2013.

[14] J. W. Qu, Q. S. Liu, J. He, and Z. P. Liu, "Study of elastoplastic damage-healing model for argillite," Chinese Journal of Rock Mechanics and Engineering, vol. 33, no. s1, pp. 3192-3197, 2014.

[15] Q. Sun, Mechanism and Method of Key Aquiclude Strata Reconstruction by Backfill Mining Technology, China University of Mining and Technology, 2019.

[16] Q. Sun, G. H. Meng, K. Sun, and J. X. Zhang, "Physical simulation experiment on prevention and control of water inrush disaster by backfilling mining under aquifer," Environmental Earth Sciences, vol. 79, no. 18, 2020.

[17] J. Zhang, T. Yang, Y. P. Tian, and B. Wang, "Experimental test for destruction law of aquiclude under action of mining and seepage," Rock and Soil Mechanics, vol. 36, no. 1, pp. 219224, 2015.

[18] C. H. Park and A. Bobet, "Crack initiation, propagation and coalescence from frictional flaws in uniaxial compression," Engineering Fracture Mechanics, vol. 77, no. 14, pp. 27272748, 2010.

[19] S. F. Wang, X. B. Li, and D. M. Wang, "Mining-induced void distribution and application in the hydro-thermal investigation and control of an underground coal fire: a case study," Process Safety and Environmental Protection, vol. 102, pp. 734-756, 2016.

[20] S. F. Wang, X. B. Li, and S. Y. Wang, "Separation and fracturing in overlying strata disturbed by longwall mining in a mineral deposit seam," Engineering Geology, vol. 226, pp. 257-266, 2017.

[21] S. Q. Yang, X. R. Liu, and H. W. Jing, "Experimental investigation on fracture coalescence behavior of red sandstone containing two unparallel fissures under uniaxial compression," International Journal of Rock Mechanics and Mining Sciences, vol. 63, pp. 82-92, 2013.

[22] M. Prudencio and M. van Sint Jan, "Strength and failure modes of rock mass models with non-persistent joints," International Journal of Rock Mechanics and Mining Sciences, vol. 44, no. 6, pp. 890-902, 2007.

[23] W. Han, Y. Jiang, H. Luan, Y. Du, Y. Zhu, and J. Liu, "Numerical investigation on the shear behavior of rock-like materials 
containing fissure-holes with FEM-CZM method," Computers and Geotechnics, vol. 125, article 103670, 2020.

[24] B. Vásárhelyi and A. Bobet, "Modeling of crack initiation, propagation and coalescence in uniaxial compression," Rock Mechanics and Rock Engineering, vol. 33, no. 2, pp. 119-139, 2000.

[25] C. A. Tang, H. Y. Liu, W. C. Zhu et al., "Numerical approach to particle breakage under different loading conditions," Powder Technology, vol. 143-144, no. 26, pp. 130-143, 2004. 